\title{
極低比速度遠心ポンプの損失解析*
}

$$
\begin{array}{llllll}
\text { 香 川 修 作*1, 松 井 } & \text { 純*2 } \\
\text { 黒 川 } & \text { 淳 } & \text { - } 2 \text {, 崔 永 } & \text { 都 }
\end{array}
$$

\section{Loss Analysis of Very Low Specific Speed Centrifugal Pump}

\author{
Shusaku KAGAWA, Jun MATSUI, \\ Junichi KUROKAWA ${ }^{* 3}$ and Young-Do CHOI \\ ${ }^{* 3}$ Faculty of Engineering, Yokohama National Univerisity, \\ 79-5 Tokiwadai, Hodogaya-ku, Yokohama-shi, Kanagawa, 240-8501 Japan
}

\begin{abstract}
In the range of very low specific speed $n_{s}$, improvement of efficiency is the most important subject in order to apply turbo machine to such a low specific speed range. The purpose of the present study is focused on the performance improvement of pump in the range of $n_{s} \leq 80\left[\mathrm{~m}, \mathrm{~m}^{3} / \mathrm{min}, \mathrm{min}^{-1}\right]$, and $\mathrm{CFD}$ simulation is performed to determine the reason why efficiency is very low. The result shows that a rapid increase of leakage rate and disk friction rate with a decrease of $n_{s}$ is the main reason of low efficiency. Also, the result shows that if the leakage loss is reduced by use of Labyrinth seal at $n_{s}=25$, the disk friction rapidly increases in spite of the leakage reduction and pump overall efficiency becomes only $5 \%$ higher.
\end{abstract}

Key Words : Turbomachinary, Fluid Machinery, Pump, Very Low Specific Speed, Loss Analysis, CFD

\section{1.は じめ に}

低流量・高揚程が特徵である比速度 $n_{s}<80[\mathrm{~m}$, $\mathrm{m}^{3} / \mathrm{min}, \mathrm{min}^{-1}$ ]（形式数 $K<0.195$ ）の極低比速度領 域では, 遠心ポンプの効率は比速度の低下とともに低 下寸る(1)ことが知られ, 従来から容積型ポンプが使用 されてきた. しかし，容積型ポンプの抱える振動や騒 音などの問題から，このような極低比速度領域での遠 心ポンプの高効率化が強く求められている.

松本らは $n_{s}=80$ で高い効率を持つ遠心ポンプの開 発を目的として, 羽根車設計諸元の性能に与える影響 ${ }^{(2)}$, ケーシング設計諸元の影響 ${ }^{(3)}$, さらに極低比速度 領域での性能向上法 ${ }^{(4)}$ 明らかにした. それらによれ ば, 極低比速度領域での羽根車水力損失は通常比速度 のポンプと同程度であり, 効率低下の原因は円板摩擦 損失の増大による機械効率の低下であり, 漏孔流量の 増加ならびに背面粗さの増加による性能向上法が示さ れている(4).

一方, 遠心ポンプの最高効率点は羽根車性能とケー シング性能の交点で与えられることに着目して, 筆者 らは極低比速度領域ではケーシング性能, とくにケー

* 原稿受付 2006 年 6 月 28 日.

*1 准員, 横浜国立大学工学府 (․․ 240-8501 横浜市保土ヶ谷区 常盤台 79-5).

*2 正員, 横浜国立大学工学研究院.

E-mail : kuro@mach.me.ynu.ac.jp
シング舌部断面積の最高効率点に与える影響が大きい ことを明らかにしてきた ${ }^{(5)(6)}$. さらに，従来あまり検 討されていない $n_{s}=60$ 以下のポンプに関して, ケー シング舌部断面積を縮小寸ることにより $n_{s}=25$ まで のポンプ性能を測定した. その結果, $n_{s}=25$ のポン プ効率は $10 \%$ 程度と大変低く, 比速度の高いポンプ を部分流量域で運転したほうが効率が高いことを明ら かにした ${ }^{(6)}$.

極低比速度領域で効率低下の原因を系統的に調べ更 なる効率向上をはかるためには，各比速度ごとに損失 の内容を分析する必要があり, 近年発達著しい数值流 体力学 (CFD) を用いた研究方法が, 流れ場および損失 に関して詳細な情報が得られるので適切と考えられる. 本研究は, 極低比速度ポンプの効率が低い原因を解 明し，かつ効率向上の指針をえることを目的として， 様々な比速度の遠心ポンプに対して CFD 解析を行い, 実験結果と比較したものである.

\section{2.おもな記 号}

$b \quad$ : 流路幅 $[\mathrm{m}]$

$c \quad: \quad$ シール部半径方向隙間 $[\mathrm{m}]$

$k$ : すべり係数

$n_{s}:$ 比速度 $\left[\mathrm{m}, \mathrm{m}^{3} / \mathrm{min}, \mathrm{min}^{-1}\right]$

$p:$ 圧力 $[\mathrm{Pa}]$ 
Table 1 Dimensions of test pumps simulated

\begin{tabular}{c|c|c|c|c|c|c|c|c|c}
\hline$n_{s}$ & $\beta_{2}\left[{ }^{\circ}\right]$ & $r_{2}$ & $b_{2}$ & $\mathrm{Z}$ & Casing type & Seal type (c) & $\gamma\left[^{\circ}\right]$ & $b_{3}$ & $r_{3}$ \\
\hline 114 & 60 & 135 & 8 & 8 & Spiral & Labyrinth (0.1) & 1.1 & 35 & 145 \\
80 & 60 & 101 & 2.5 & 6 & Spiral & Wearing ring (3.5) & 0.9 & 20 & 104 \\
60 & 60 & 129 & 5.2 & 6 & Circular & Wearing ring (5) & - & 20 & 138 \\
40 & 60 & 126 & 6.3 & 6 & Circular & Wearing ring (5) & - & 20 & 138 \\
25 & 60 & 126 & 6.3 & 6 & Circular & Wearing ring (5) & - & 20 & 138 \\
\hline
\end{tabular}

$b_{2}, c, r_{2}, r_{3}, b_{3}:[\mathrm{mm}]$

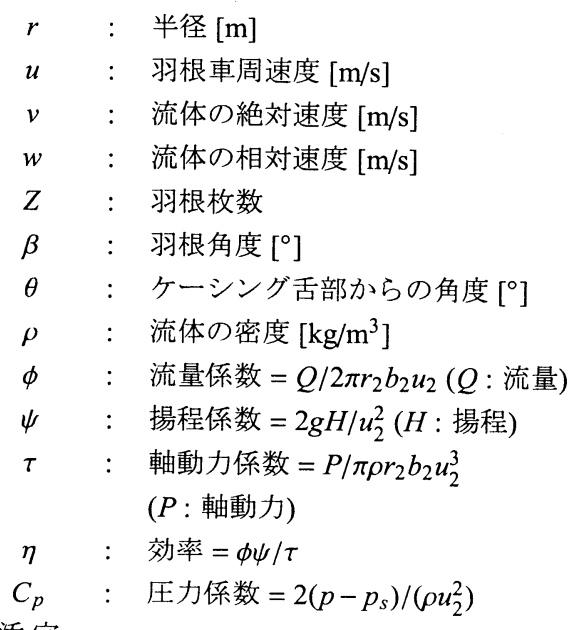

添字

2, 3, s : 羽根車出口, ケーシング基礎円, 吸込み口 $m, \theta$ : メリジアン方向, 周方向成分

$Q, q, t h$ : ポンプ流量, 漏れ流量, 理論

$\overline{\bar{A}} \quad: A$ の流量平均值

$=\int_{0}^{b} \int_{0}^{2 \pi} A r v_{m} d \theta d z / \int_{0}^{b} \int_{0}^{2 \pi} r v_{m} d \theta d z$

$\bar{A} \quad: \quad A$ の断面平均值

$=\int_{0}^{b} \int_{0}^{2 \pi} A r d \theta d z / 2 \pi r b$

\section{CFD 解析方法}

$3 \cdot 1$ 解析対象遠心ポンプ 様々な比速度を持つ 遠心ポンプの CFD 解析を行うために, データの明ら かな $n_{s}=114^{(5)}, 80^{(4)}, 60^{(6)}$, さらに $n_{s}=60$ のポンプ の舌部断面積を縮小してえられた $n_{s}=40^{(6)}, 25^{(6)}$ のポ ンプを解析対象とした. 図 1 には一例として比速度 60 の遠心ポンプを示し, 表 1 には解析を行ったポンプお よび羽根車の諸元を示す. どの羽根車もクローズド型 かつ高揚程を得るために羽根車出口角 $\beta_{2}=60^{\circ}$ である.

$n_{s} \leq 60$ では，通常の設計法を用いて渦巻きケーシ ングを設計すると巻き角 $\gamma$ が著しく小さくなり, 円形 ケーシングの方が適している(6)ので, 表 1 中の比速度 60 以下では円形ケーシングを用いている.この場合 $r_{3}$ はケーシング外半径をあらわしている.

表 1 中にはライナリング半径隙間 $c$ を併せて示して おり, 比速度 80 以下においてライナリング隙間が通

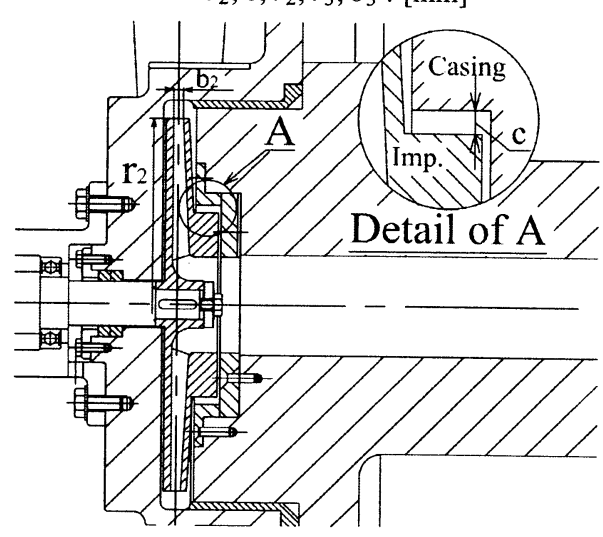

Fig. 1 Configuration of test pump

常の遠心ポンプの場合 $(0.3 \mathrm{~mm}$ 程度) と比較して著し く大きくなっている.これは，比速度 80 において，ラ イナリング隙間が大きい方が効率が向上するという実 験結果 ${ }^{(4)}$ による. また, 通常の設計法では羽根車出口 幅 $b_{2}$ が比速度の低下とともに小さくなり，その製作 限界（ $b_{2} \leq 1 \mathrm{~mm}$ ) を越えてしまうが, 極低比速度領域 では $b_{2}$ を大きく選定したほうが効率が高く, 右上が り不安定性能が生じにくい(4)ので, ここでは $b_{2}$ をあ えて大きく設計している. 羽根車周速度 $u_{2}$ に基づく レイノルズ数は $R e=u_{2} r_{2} / v=2.7 \sim 3.2 \times 10^{6}$ である.

3.2 数值解析方法 CFDは, 市販コードANSYS $\mathrm{CFX}^{(7)}$ を使用した. ANSYS CFX は基礎方程式として 時間平均 Navier-Stokes 方程式と連続の式を，有限体 積法で離散化し時間平均流れを解くものであり, 乱流 モデルとして $k-\omega$ モデルを採用し，壁面はすべり無 しとし壁関数を使用した. 入口側境界条件として一様 流速, 出口境界条件として断面内平均静圧一定とした. 解析は, 羽根とケーシング舌部の相対位置を変化させ る非定常解析を行った. なお, 回転系と静止系の計算 格子との間は, Transient Rotor Stator の手法を用いて 接合した. 図 2 には一例として比速度 80 の遠心ポン プの解析格子を示す. なお, どの遠心ポンプにおいて も計算点は 110 万程度である.さらに図 2(c) に示すよ うに羽根車前面および背面漏孔流路もモデル化してい る. 狭い隙間では流路幅方向に最低でも計算点を 8 点 確保し, 計算点を倍の 16 点としても漏れ流量および 


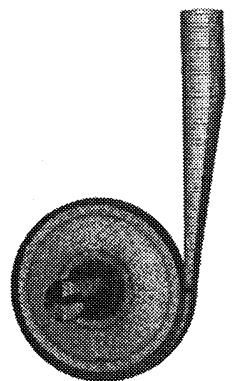

(a) Outside view of pump grid

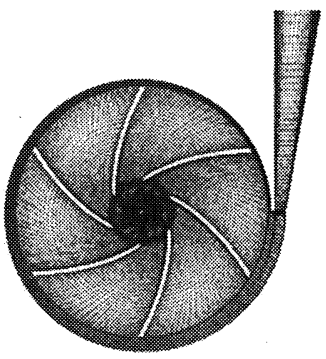

(b) Front view of pump grid

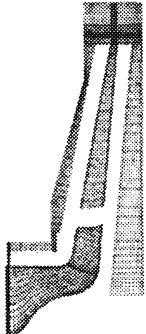

(c) Side view of pump grid

Fig. 2 Computational grid of centrifugal pump at $n_{s}=80$

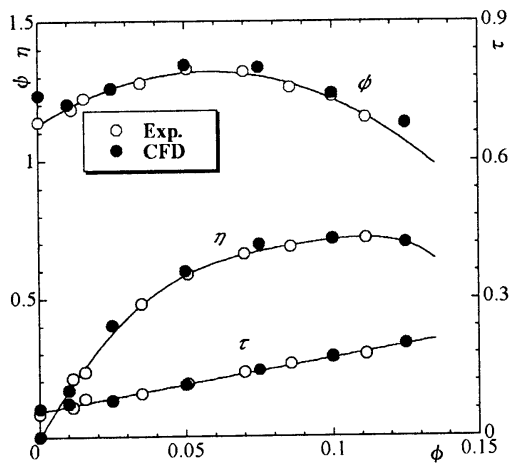

(a) $n_{s}=114$

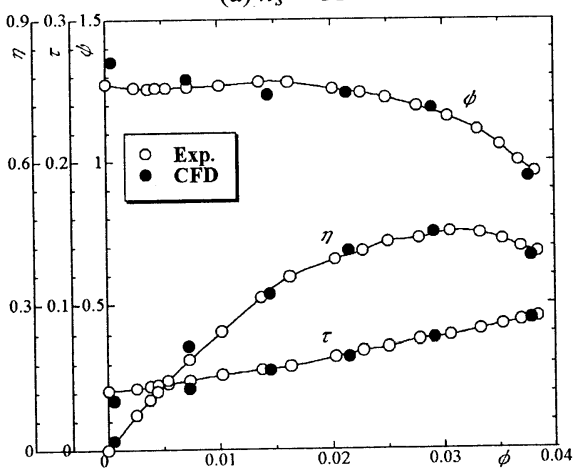

(c) $n_{s}=60$

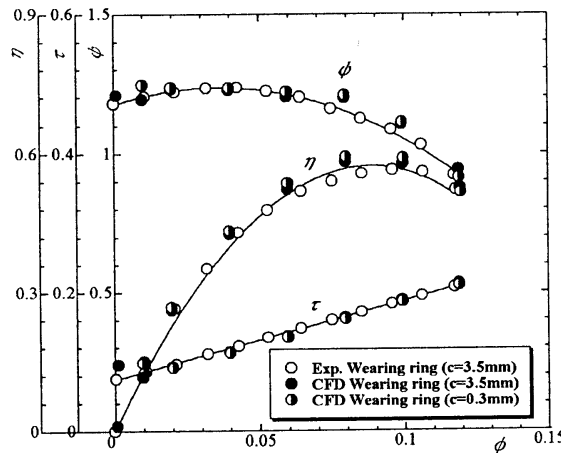

(b) $n_{s}=80$

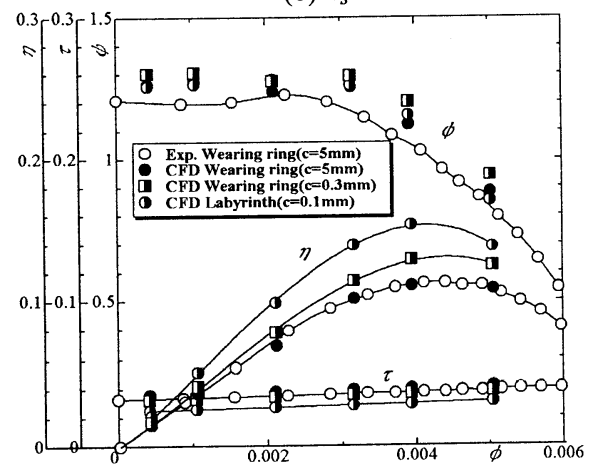

(d) $n_{s}=25$

Fig. 3 Comparison of performance curves between CFD simulation and Experiment

円板摩擦の計算値に差がないことを確認している.

3.3 軸動力および効率の分析 効率低下の原因 を明らかにするために，本研究ではポンプ軸動力およ び効率の分析を行う. 遠心羽根車の軸動力は羽根車入 口および出口での角運動量変化より, 以下のように与 えられる(8).

$$
\tau=\left(\phi_{Q}+\phi_{q}\right) \psi_{t h}+\tau_{\text {disk }}+\tau_{R}
$$

ここで， $\tau_{R}$ は羽根入口逆流に基づく動力損失である. また，遠心ポンプの揚程係数 $\psi$ は，理論揚程係数 $\psi_{t h}$ から各流路の無次元水力損失 $h_{\text {loss }}=\Delta H_{\text {loss }} /\left(u_{2}^{2} / 2 g\right)$ を
差し引くことにより与えられるので, 式 (1) は以下の ように変形できる.

$$
\begin{aligned}
\tau= & \phi_{Q}\left(\psi+h_{\text {imp. }}+h_{\text {diffuser }}+h_{\text {casing }}\right) \\
& +\phi_{q} \psi_{t h}+\tau_{\text {disk }}+\tau_{R}
\end{aligned}
$$

上式中の右辺各項はそれぞれ, ポンプ水動力 $\phi_{Q} \psi$, 羽 根車水力損失動力 $\phi_{Q} h_{i m p}$, 平行壁ディフューザ水力損 失動力 $\phi_{Q} h_{\text {diffuser }}$, ケーシング水力損失動力 $\phi_{Q} h_{\text {casing }}$, 漏れ損失動力 $\phi_{q} \psi_{t h}$, 円板摩擦損失動力 $\tau_{\text {disk }}$, 羽根車 入口逆流に基づく動力 $\tau_{R}$ であり, 各水力損失は各位 置での流量平均全圧の差から求め, $\tau_{R}$ は羽根車入口 での角運動量変化より求めた ${ }^{(9)}$. 


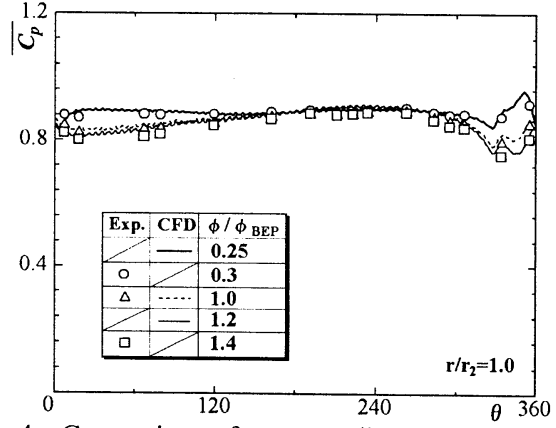

Fig. 4 Comparison of pressure distribution at $n_{s}=60$

\section{4. 実測値と CFD 解析の比較}

図3(a)から (d) は全供試ポンプに対して，CFD 解析 結果を実測值と比較したものである. 全般的に揚程を 含めて, 軸動力が実験と広い比速度範囲で良好に一致 することから，軸動力曲線に影響が大きい漏れ流量お よび理論揚程も正しく解析できていると考えられ，ま た羽根出口角の大きい羽根車での右上がり不安定性能 が CFD 解析でも良好に予測できている.

なお，図3(d) に示寸比速度 25 では揚程が多少高く でているが，これは吸込み管における強い旋回流れの 影響と考えられる.すなわち，本研究で採用した $k-\omega$ モデルに代表される 2 方程式乱流モデルでは旋回流れ に対して計算精度が低下することが知られており，比 速度 25 のような通常のポンプの締切点に近い領域で 運転されるポンプの揚程の予測が難しいことを示して いるが，比較的良好に予測しているといえる.

図 4 には比速度 60 のポンプでの $r / r_{2}=1.0$ におけ る周方向圧力分布の比較を示しており，計算值と実験 值の流量が多少異なってはいるが，比較的良好に一致 することから，ポンプ内部の流れ場についても実験を 再現できていると考えられる.

\section{5. 極低比速度遠心ポンプの損失解析}

図 5(a)には, 解析した各比速度の遠心ポンプの最 高効率点での水力効率 $\eta_{h}=\psi / \psi_{t h}$, 機械効率 $\eta_{m}=(\tau-$ $\left.\tau_{\text {disk }}\right) / \tau$, 体積効率 $\eta_{v}=\phi_{Q} /\left(\phi_{Q}+\phi_{q}\right)$ を示寸. なお, 参 考値として円板摩擦損失動力の全軸動力に対する比 $\tau_{\text {disk }} / \tau$ を示している. 図 5(a) より比速度の低下ととも に, 体積効率 $\eta_{v B E P}$ の低下が著しく大きいことが明ら かとなる。これは, 比速度の低下に伴ってポンプ流量 が急減少するので, 漏れ流量の影響が相対的に大きく なるためである，また， 円板摩擦損失も比速度の低下 と共に相対的に増加するので, 機械効率 $\eta_{m B E P}$ も低下 しているがその低下量はあまり大きくない，一方，比 速度 40 以下では水力効率 $\eta_{h B E P}$ の低下が著しくなる.

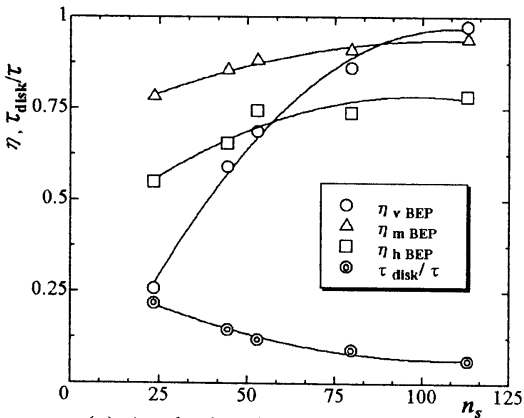

(a) Analysis of pump efficiency

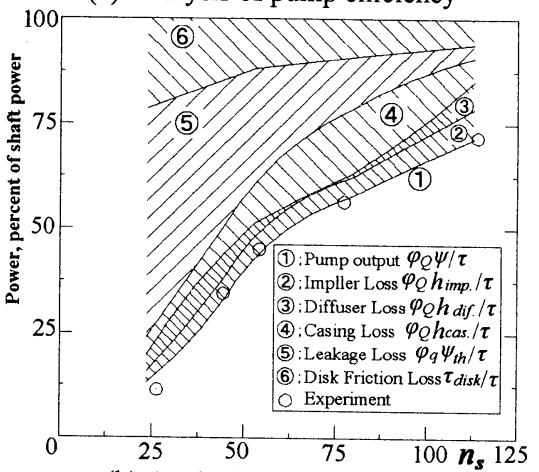

(b) Analysis of shaft power

Fig. 5 Analysis of efficiency and shaft power at BEP

図 5(b) には, CFD 解析を行った全比速度の遠心ポ ンプ最高効率点において，式(2)によって整理した軸 動力に対する各損失動力の百分率を示し, 合わせてポ ンプの各 $n_{s}$ における最高効率の実測值を併記してい る. 解析した各比速度のポンプは, 設計諸元が異なる ので一概に比較はできないが, 図 5(b) は極低比速度 領域での性能向上の指針を与える. 図 5(b) において 顕著な点は, 図 5(a) 同様, 比速度の低下とともに漏れ 損失動力の相対割合の著しい増加である. 特に, 比速 度 60 以下での漏れ損失動力および円板摩擦損失動力 の割合が非常に大きくなっており，比速度 25 では漏 れ損失動力の割合が約 $50 \%$ に, 円板摩擦損失動力の割 合が約 25\%にも達している.

以上より，比速度 60 以下で効率向上に最も効果的 なのは漏れ流量および円板摩擦の低減であることが明 らかとなる．なお，羽根車入口逆流に基づく損失動力 $\tau_{R}$ の軸動力に占める割合は全比速度範囲でたかだか $1 \sim 3 \%$ 程度であった. 極低比速度では, 最高効率点に おいても入口逆流が存在するが, 羽根車内外径比が比 較的大きいので，その規模が必ずしも大きくならず， $\tau_{R}$ の全軸動力に対する割合は小さい.

図 5(a)において興味哚いのは, 水力効率の絶対值 が通常のポンプに比べて大変低いことであり, 図 3 の 


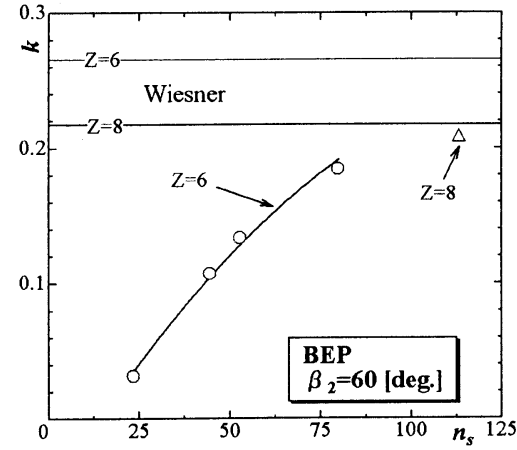

Fig. 6 Slip factor of very low $n_{s}$ pump

揚程係数から計算される理論揚程係数 $\psi_{t h}$ が著しく大 きくなる.この原因を検討するために，図 6 に解析を 行った全比速度の遠心ポンプの最高効率点におけるす べり係数 $k$ を示し, 合わせて通常の比速度ですべり係 数を良好に予測するWiesnerの式 ${ }^{(10)}$ も示している. 図 6 より比速度 80 以下では比速度の低下とともに, 寸 べり係数が 0 に近づくことがわかる. すなわち, 羽根 車出口流れが羽根に沿ったまま流出する羽根数無限大 の場合に近づくことになる.

この原因を検討するために, 図 7(a)に比速度 25 の 場合の最高效率点において羽根中央断面での相対速度 ベクトルを示し, 図 7(b) には羽根出口において幅方 向に断面平均した周方向の速度分布 $\left(\overline{v_{m 2}} / u_{2}, \overline{v_{\theta 2}} / u_{2}\right)$ を羽根 1 ピッチ分示している. 図 7(a) より明らかなよ うに, 最高効率点においてさえ羽根負圧面から圧力面 にかけて大きな再循環流領域がどの羽根間流路にも存 在し，羽根数無限大の流れとは大きく異なり，図 7(b) より羽根間流路の中央で $\overline{v_{m 2}} \leq 0$ となる出口逆流が生 じている。

この逆流は, 羽根出口における相対速度が流路うず のために羽根間中央で周方向を向き, コリオリカが軸 中心に向かって作用するために引き起こされる. した がって, 逆流域では相対速度の周方向成分 $\overline{w_{\theta 2}}$ が最大, すなわち絶対速度の周方向成分 $\overline{v_{\theta 2}}$ が最小となり, 図 7(b)に示すように著しく大きな速度ひずみを生ずる. この $\overline{v_{\theta 2}}$ を羽根車全周に亘って流量平均したものが $\overline{\overline{v_{\theta 2}}}$ であり，理論揚程 $\psi_{t h}=\overline{\overline{v_{\theta 2}}} / u_{2}$ は著しく大きくなる.

羽根出口における著しい速度ひずみは一様化する過 程で大きな混合損失を生じるが，図 5(b)によれば，混 合損失を含む固定流路の損失動力 (3)+(4) はかなり小 さく, 全損失動力の $10 \%$ 程度である. 比速度 25 の羽 根車では, 水力損失ヘッドは理論揚程の $45 \%$ にも達す るのに，水力損失に基づく損失動力 $\phi_{Q} \sum h_{\text {loss }}$ は全動 力損失のわずか $13 \%$ 程度である. すなわち, 単位重量 当りの損失は著しく大きいが，その損失動力 $\phi_{Q} \sum h_{\text {loss }}$

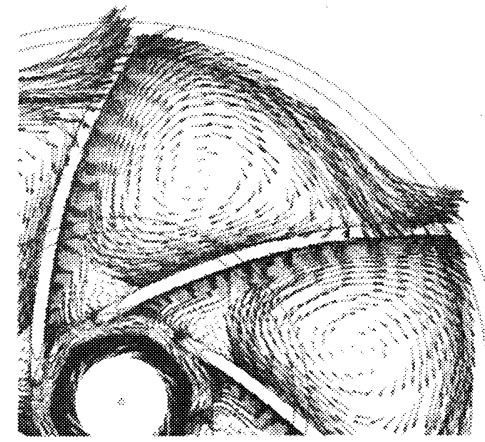

(a) Velocity vector

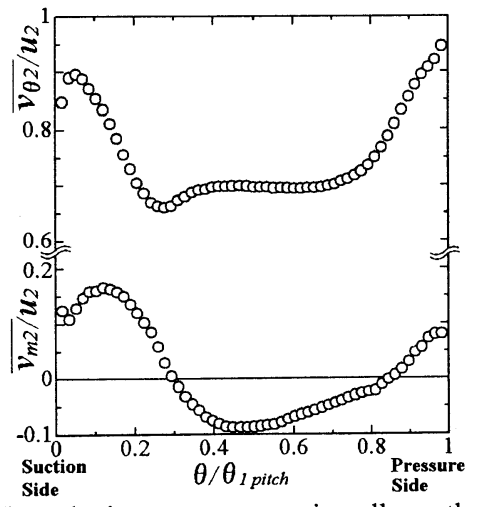

(b) Velocity component at impeller outlet

Fig. 7 Velocity distributions at the BEP of $n_{s}=25$

は小さいということであり，その原因は羽根車を流出 する流体の大部分が漏れとして吸込み側に戻ってしま うことにある $\left(\eta_{v}=30 \%\right)$.このことはまた， $n_{s}$ が著し く低い範囲 $\left(n_{s} \simeq 25\right)$ では, ポンプ流量が少ないので 体積効率を向上させた上で羽根車出口流れを改善する ことにより，極低比速度領域での効率向上が期待でき ることを示唆している.

前述の結果より極低比速度領域で効率向上を図るた めには，漏れ損失動力の低減が必須であることが判明 した. そこで, 比速度 80 および 25 のポンプに対して, ライナリング隙間を通常の值 $c=0.3 \mathrm{~mm}$ に設定した場 合の計算結果を前出の図 3(b) および (d) に併記した. 図 3(b) および (d) より，ライナリング隙間が特別に広 い場合とくらべて, 効率は比速度 80 ではほとんど変 化せず，比速度 25 では $2 \%$ 程度しか向上しないことが わかる。 この場合，比速度 25 のポンプにおいて，効 率を分析したものを図 8(a) に示す．体積効率は多少向 上するが，低流量域では羽根車通過流量 $\left(\phi_{Q}+\phi_{q}\right)$ の 減少による $\overline{\overline{v_{\theta 2}}}$ 増加のため $\psi_{t h}$ が増加して水力効率が 低下し，さらに全流量域で機械効率も低下している. ライナリング隙間の大幅な変化にも関わらず，体積効 率が変化しない原因を明らかにすべく，ポンプ前面漏 


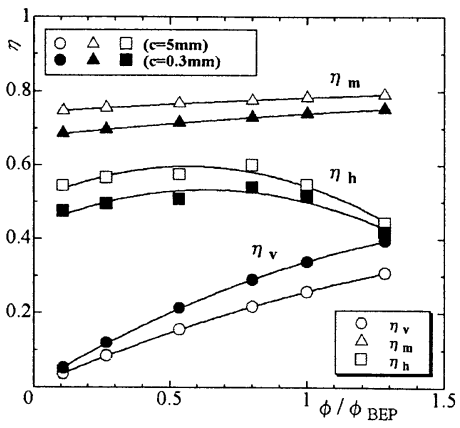

(a) Influence of seal clearance

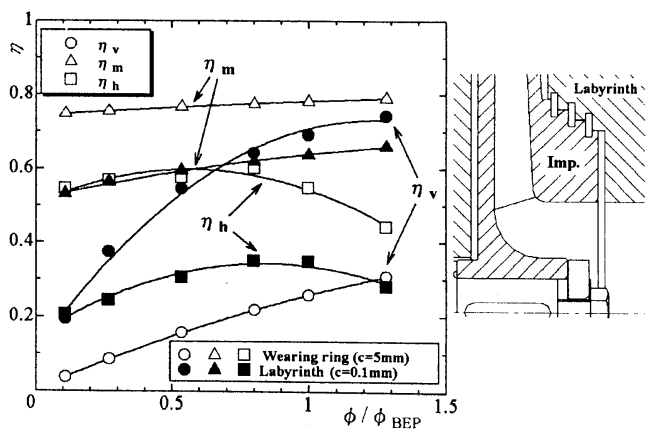

(b) Minimum clearance case by Labyrinth seal

Fig. 8 Influence of seal clearance on efficiency at $n_{s}=25$

れ流路における半径方向圧力分布を検討したところ, ライナリング隙間が大きくても隙間前後の圧力差はほ ぼ 0 に近いことが判明した。これらのことから，極低 比速度領域では通常製作されるライナリング隙間にし ても，全効率に及ぼす影響は少ないと結論される.

しかし，図 5(b) によれば比速度 60 以下では漏れ損 失動力が全損失動力の $25 \sim 50 \%$ 程度を占めているの で, ライナリング隙間を極限まで狭めることができれ ば，全効率の向上が期待できる.そこで，図 8 右に示 すラビリンスシールを用いてライナリング隙間を限界 まで狭めた $(c=0.1 \mathrm{~mm})$ 計算を行った. その場合の性能 曲線を図 3(d) に，効率の分析を図 8(b) に示す．図 3(d) および図 8(b) より体積効率は最高効率点で 40\%程度 向上寸るが，その代わり全流量域で水力効率が急低下 し, 円板摩擦損失割合の増加による機械効率の低下も 見られる. その結果，全効率は約 5\%程度しか向上し ないことがわかる. 水力効率の低下は主に, すべり係 数が流量とともに大きく変化することが原因である.

\section{6. 結 論}

極低比速度領域で比速度の異なる 5 種類の遠心ポン プを用いて, 各比速度に対する損失分析を行い, 以下 の結論を得た。

(1) 比速度の低下とともに, 漏れ損失動力および円 板摩擦損失動力が急激に増加し，とくに比速度 25 で は漏れ損失動力の割合が約 $50 \%$ に，また円板摩擦損失 動力の割合が約 $25 \%$ にも達する.

(2) 最高効率点の水力効率は, 比速度 50 以上ではあ まり変化しないが, 比速度 50 以下では比速度の低下 とともに急低下する. これは, 羽根車出口逆流により 流量平均周速度が増加するためすべり係数が著しく減 少し理論揚程が増大することが主な原因であり，水力 効率は低いが水力損失動力は必ずしも大きくはない.
(3) 極低比速度領域では，漏れを減らすと円板摩擦 動力および羽根車内の水力損失が増加し, 全効率はあ まり変化しない，しかし，漏れを極限まで減少できれ ば，効率を 5\%程度向上させることができる．

\section{文献}

(1) Stepanoff, A. J., Centrifugal and Axial Flow Pumps, 2nd ed., (1957), pp.69-89., John Wiley and Sons.

(2) Matsumoto, K., et al., Performance of Very Low Specific Speed Impeller (in Japanese), Turbomachinery, Vol.25, No.7, (1997), pp.337-345.

(3) Matsumoto, K., et al., Study on Optimum Configuration of a Volute Pump of Very Low Specific Speed, Transactions of the Japan Society of Mechnical Engineers, Series B, Vol.66, No.644, (2000), pp.1132-1139.

(4) Matsumoto, K., et al., Performance Improvement and Peculiar Behavior of Disk Frction and Leakage in Very Low Specific-Speed Pumps, Transactions of the Japan Society of Mechnical Engineers, Series B, Vol.65, No.640, (1999), pp.4027-4032.

(5) Kurokawa, J., et al., Performance of Low Specific Speed Centrifugal Pump (in Japanese), Turbomachinery, Vol.18, No.5, (1990), pp.300-307.

(6) Kagawa, S,. et al., Performance of Very Low Specific Speed Centrifugal Pump with Circular Casing, Transactions of the Japan Society of Mechnical Engineers, Series B, Vol.71, No.705, (2005), pp.1821-1828.

(7) ANSYS Inc., ANSYS CFX Documentation Ver 5.7.1, (2004), Waterloo, Ontario, Canada.

(8) Senoo, T., Slip Factor - Internal Flow and Disk Frction of Centrifugal Impeller (in Japanese), Turbomachinery, Vol.10, No.2, (1982), pp.110-114.

(9) Kurokawa, J., et al., Inlet Reverse Flow Model and Prediction of Theoretical Head and Water Power of Mixed-Flow Pumps, Transactions of the Japan Society of Mechnical Engineers, Series B, Vo.59, No.557, (1993), pp.143-149.

(10) Wiesner, F.J, A Review of Slip Factors for Centrifugal Impellers, Transactions of ASME, Journal of Engineering for Power, Vol.89, No.4, (1967), pp.558-572. 